\title{
Ergo-Biopsychosocial Approach to Support the Quality of Life of Small Housing Inhabitants
}

\author{
Markus Hartono $^{1^{*}}$, Antonius Johanes Tjahjoanggoro², \\ Marselius Sampe Tondok ${ }^{2}$, Indri Hapsari ${ }^{1}$
}

\begin{abstract}
A study on the intervention of human factors engineering (known as ergonomics) on sustainable living based on biopsychological needs was conducted, taking samples of small housing inhabitants. In total, 90 participants were involved. Those who were living in small housings have a significant challenge of how to live comfortably given very limited space. The measurement of the quality of human life through WHOQOL-BREF (World Health Organization Quality of Life$B R E F)$ and ergonomics-based usability were used to describe the current human well-being satisfaction, to propose the modified physical facilities, and to validate the proposed design and improvement. Regarding ergo-biopsychosocial approach, this study showed that there was a close relationship between the comfort of the physical environment and the satisfaction of biopsychosocial aspects of inhabitants. The implementation of more ergonomic multifunctional facilities and furniture has brought significant impact on the inhabitant's quality of life. Hence, the principle of human needs to be more humanized was proven.
\end{abstract}

Keywords: Biopsychosocial, ergonomics, sustainability, quality of life, small housing.

\section{Introduction}

The Quality of life (QoL) is a very interesting topic in any form of human activity. QoL and well-being are closely significantly related. There are 4 components of subjective well-being closely related to QoL [1, 2], namely, pleasant affect, unpleasant affect, life satisfaction, and domain satisfaction. Related to life satisfaction and quality, humans have a common desire to change their life, recall their past, and think of their partner's life. The quality of human life is defined as a situation of a person or individual receives sufficient value and context according to his perception. It includes personal, psychological, physical, mental, social, and environmental-based safety and health.

QoL is not only covering employment and wealth, but also a good environment, mental health, recreation, and social belonging. It concerns the improvement of people's goals within major life settings. Staying at home with family is also considered a significant component of QoL life settings. It is concerned with the degree to which the individuals enjoy their own quality of life within the family setting. More importantly, individuals within a family should extend their goals to live in harmony with their community and society. It can't be denied that a comfortable and good feeling at home will bring a significant impact to all individuals to live in.

\footnotetext{
${ }^{1}$ Faculty of Engineering, Department of Industrial Engineering, University of Surabaya, Jl. Raya Kalirungkut, Tenggilis, Surabaya 60293, Indonesia. ${ }^{2}$ Faculty of Psychology, Department of Psychology, Univeristy of Surabaya, Jl. Raya Kalirungkut, Tenggilis, Surabaya 60293, Indonesia.

Email: markus@staff.ubaya.acid

* Corresponding author
}

It is quite challenging to see and recognize people living in a relatively small space and dimension in a high-rise building. It may refer to flats, which usually have a total area of less than 25 square meters. The dramatic adaptation and regular adjustment are required to those who are living in that small housing in terms of daily activities and movements. It, potentially, leads to quality of life and living performance [3]. Due to the rapid social, economic, and environmental growth in city urban area, living and staying in a small vertical housing has been popularized. Local government has introduced and approached the local inhabitants to stay, thereby providing sufficient physical facilities such as public kitchen, parking lot, rest area, children playground and so on. It looks like an apartment complex with a very simple and ordinary scope of facilities. The dimension of a small housing is meant to be enough to live in simply. Actually, living in a smaller house is increased significantly nowadays. It may be driven by the practicability of living style, economic value, facilities provided, and social factors. Other reasons may include the potential for stratification to reduce the cost of each unit and very limited space available in an urban area. Small housing is also considered as a social space, a place to live and share.

There is a quite popular small housing or flat complex in Surabaya, Indonesia, called Penjaringan Sari. It is also known as Rusun Penjaringan Sari (RPS). This flat complex was established in 2005. It has four types, namely, RPS I, II, III, and IV. Each room of each flat type is rented with various monthly rates, as follow: 1st floor for IDR 96k, 2nd floor for IDR 86k, 3rd floor for IDR 76k, 4th floor for IDR 62k, and 5th floor for IDR 43k. It seems that there is a positive trend of 
people choosing a small housing complex to stay. The quality of life will be a concern, then.

Living in a small housing complex or flat may bring a significant challenge for human personal, social, and other basic needs. It should not be a burden on family quality life. Since it deals with human physically, mentally, and socially, then Human Factors Engineering (HFE), or ergonomics may deal with the issues of QoL in the small housings. Ergonomics deals with both limitations and capabilities of a human. Limitations include constraints such as small space and dimension of housing, public space for cooking, limited space for parking, and so forth. Capabilities are related to the survival and ability of humans living and staying in a stressful environment with no significant difficulties. Humans are, actually, quite flexible in adjusting to any harmful or uncomfortable conditions. The understanding of human characteristics and components of a system is critical in optimizing the human-system performance [4]. Inherently, the human is a core entity in a particular socio-technical system. Hence, ergonomics-based issues such as cognitive, affect, physical, and organizational components are critical to small housing inhabitants to accommodate and adapt.

Apart from ergonomics, another approach called a biopsychological model is proposed to understand the quality of living. It has been addressed by Engel [5], and it is potential in understanding how the inhabitants live in a very limited and small housing. This model comprises biological, psychological, and social aspects. Biological means biochemical and genetic factors. Psychological deals with personality, emotions, and behavior factors. Social refers to familial, cultural, and socioeconomic dimensions.

Both internal and external factors will be considered. Hence, the combined approach of ergonomics and biopsychosocial are deemed critical to human wellbeing. There is less exploration of this combined model for those who are living in a small housing complex. It is proposed as a research gap.

This study has two main objectives. According to the preliminary literature review, first, it proposes an applicative framework of the ergo-biopsychosocial model in addressing the QoL of people staying in a small housing complex. Afterwards, for the second objective, it is to apply the concept to a case study on RPS small housing complex. The ergonomics deals with the redesign of physical multifunction facilities, whereas, the biopsychosocial approach assesses the QoL. Besides, usability testing is conducted to see the impact of proposed improvement on the ergonomics intervention.

\section{Methods}

\section{Ergonomics and Biopsychosocial}

Ergonomics and biopsychosocial approaches are dominant in this study. They are combined as ergobiopsychosocial approach. Ergonomics, again, stresses the human capabilities, performances, and limitations. Adaptation and adjustment are the key points for human survival mode in ergonomics. Minimum effort with maximum performance should be promoted. The second major approach, namely biopsychosocial, addresses the assessment of QoL based on three factors (i.e., biological, psychological, and socio-environmental). It is a unified model which assesses the total quality of work life. It addresses the various field of life consisting of health, psychology, and human development. In other words, the subjective evaluation of the human quality of life is expressed in all cultural, social, and environmental contexts. The biological aspect highlights genetic and biochemical. The psychological is concerned with mood, personality, and behavior. The social factors refer to cultural, familial, socioeconomic, and medical. A person may have a genetic problem predisposition, but he/she can maintain both good social and cognitive interaction.

The definition of biological, psychological, social, and environmental aspects is based on the concept of QoL according to the World Health Organization (WHO). QoL covers an extensive range of domains in life. It discusses how an individual achieves a good quality of daily life. An individual proposes expectation which meets the standard level of life. The life expectancy is quite complex; it deals with the values, goals, and socio-cultural context in which individuals stay and interact with one another. At the final stage, life satisfaction as one's subjective well-being is expected. Life satisfaction includes physical health, education, wealth, safety, security to freedom, and environment. According to Barcaccia [6], QoL covers several issues, such as (1) Subjective life satisfaction and values. (2) Multidimensional aspects of life, e.g., physical health, psychological state, level of independence, family, education, wealth, local services and transport, social relationships, housing, and environment. (3) Cultural aspects, values, personal goals and expectations of life. (4) The multidisciplinary medical team especially a perspective approach on psychosocial needs, not just physical cares. (5) Interpretation of facts "the real quality of life". (6) The acceptance level of the current condition and how to deal with negative thoughts and emotions caused by a certain condition.

The biological aspect of QoL refers to the quality of physical health, which is marked by the presence or absence of pain. This model provides an improvement 
strategy of handling factors influencing individual stress. It links the environmental demands to individual well-being and health. According to Frankenhaeuser [7], the various demand of work influences the cognitive process in the cortex of the human brain. As a result, stress hormones will be produced, and they facilitate both physical and mental adjustment in coping with environmental demands. In the long-term, this prolonged stress will bring damaging effects. High level of cortisol which leads to cardiovascular disease, should be highly considered. Psychological aspects refer to selfacceptance, the ability to enjoy life, and meaningfulness in life. Due to various levels of working demand, our body may experience two-state stress, ranging from negative to positive emotions or affects. The positive emotions include engagement and determination of goal achievement, whereas, the negative emotions may refer to distress, giving up, and helplessness. Social and environmental aspects include socio-economical, cultural factors, and socioenvironmental. It also covers work issues and family circumstances. Regarding the inhabitant's living, the aspect of social relations reflects housing or living situation; it is one's ability to establish relationships with other flat residents, as well as social support obtained from other flat residents. Environmental aspects indicate one's satisfaction with physical conditions and supporting facilities in the flat.

Ergonomics promotes the provision of right product or job to the right user at the right time in a sociotechnical system. The designer should understand well the user characteristics. In terms of ergonomics, anthropometry, and cognitive workload are closely related to the biopsychosocial model. Anthropometry deals with the physical comfort of user and customer, considering various population, different gender, sufficient nutrition, and physical exercise [8; 9]. It is to ensure that the design fits the user's physical dimensions. Once it is well designed, significant QoL will be achieved. A better QoL will be promoted.

According to IEA [4], ergonomics is mentioned as a discipline concerned with the understanding of mutual interaction between humans and other elements of a system in order to achieve the human wellbeing and the optimum system performance. Ergonomics is deemed to increase working and living productivity. Apart from productivity, working comfort is also considered as the objective of ergonomics implementation. Productivity and comfort are the end-result of a certain process.

In the urban city, living in vertical buildings with small standardized dimensions for each unit is a big challenge. Economic, social, and environmental sustainability aspects are questioned about how the inhabitants are staying and doing their daily practices. Sometimes, it is difficult for the inhabitants to adapt to the environments which influence their satisfaction and quality of life. Due to the governmental pressures on the greener environment, it is imperative to have units with smaller dimensions located in a more attractive large common area. Thus, the reduced inhabitant space will be potentially bringing impact on the quality of indoor space and the quality of a family's life.

Previous research on small vertical buildings has been conducted by taking a case study on flats in Natal, the northeast region of Brazil [3]. It took housing units ranged between $50 \mathrm{~m} 2$ and $60 \mathrm{~m} 2$ with two bedrooms. Customer satisfaction has been measured according to the perception of a building's interior space and function. The assessment of the room comfort was based on specific needs of the family. That study considered critical facilities to solve family-based problems, e.g., use of a wheelchair and design of bathroom and bedroom for the elderly. In the bathroom design, the vertical- and horizontalbased safety bars were installed accompanied by tissue paper and towel holder access to the elderly considering the 5th percentile measures. Regarding the bedroom design, there was an intervention of demolishing the wall between rooms and placing a wardrobe with four doors.

Living in small housing units of the vertical building will have a challenge on functionality and reliability of housing units and user satisfaction, given very limited space. Thus, modification of building and equipment and furniture is needed, such as demolition of walls, re-layout of area, re-design furniture. If the initial unit design is not flexible, then there is a high cost of intervention and re-modification as a potential consequence.

How do people adapt to the limited space of vertical housing? How do people cope with their stress and difficulties? It is a critical question asked by many inhabitants of flat in the vertical housing complex. It is a call for ergonomists to address, especially the inclusion of people with special needs who live in the small housing/flat [10]. Adapting to the various characteristics of people is an opportunity for designers and practitioners. Dealing with a special design for special needs will need a more accurate and detailed evaluation of two aspects, namely, (i) the individual evaluation (e.g., work interest, skills, and disabilities) and (ii) the ergonomic aspects (e.g., job demands and characteristics).

Inherently, ergonomics is indispensable since this discipline can facilitate the adjustments to the job through the knowledge of the task of the cognitive, physical, and organizational demands, as well as deal with people of special needs. Since all housing units of the vertical building are similar in size and shape attached to public facilities, then workplace accommodation is required. The workplace accommodation 
addresses a customized, individualized approach to enable people with special needs to carry out more productive tasks. In small housing/flat area, it includes ensuring work procedures which are accessible to all, providing assistive devices, and modifying public facilities which fit all inhabitants. With new technology advance, workplace accommodation may utilize voice recognition systems, screen reading systems, and hearing aids systems [10].

Green building as a sustainable building practice has been deemed a hot issue in recent years due to environmentally friendly awareness. Sustainability in building and living is defined as development which meets the people, planet, and profit demands, also known as a triple bottom line. It means a place to ensure individuals are safe and protected during the design, construction, operation, and demolition of a building [11]. Hence, incorporating ergonomics into sustainable development will enhance human performance, productivity, and well-being. It covers both the individual and system level. Once the building is constructed, how to use and operate the building is a challenge. The goal is to maintain green practices. The principles of $3 \mathrm{Rs}$, namely, reduce, reuse, and recycle, are encouraged [11].

Nevertheless, there is no specific and generic adjustment which applies to all types of environment. Each situation is unique and different from one another. Ergonomics has the potential to overcome that challenge.

\section{Applicative Framework Development}

At the initial stage, an applicative framework of ergobiopsychosocial approach is done. It starts with the choice of a small public housing complex or known as flat. A case study at RPS small housing complex at Surabaya, Indonesia was selected. It is one of the popular small housing complexes, managed by the local government of Surabaya.

Afterwards, the measurement of the biopsychosocial dimension is conducted. It is done through the measurement of importance and perception of quality living for all inhabitants. The discrepancy between perception and importance provides the mapping of quality of living. It is then analyzed. Also, the inhabitant's needs and necessities will be considered as a complement of the living standard at the small housing. Once there is a discrepancy between what is perceived and required by the inhabitant, there will be a gap. A gap analysis should be conducted to see which items of quality living should be improved. The instrument of QoL adopted from WHO is considered. It is known as WHOQOL-BREF (World Health Organization Quality of Life-BREF).

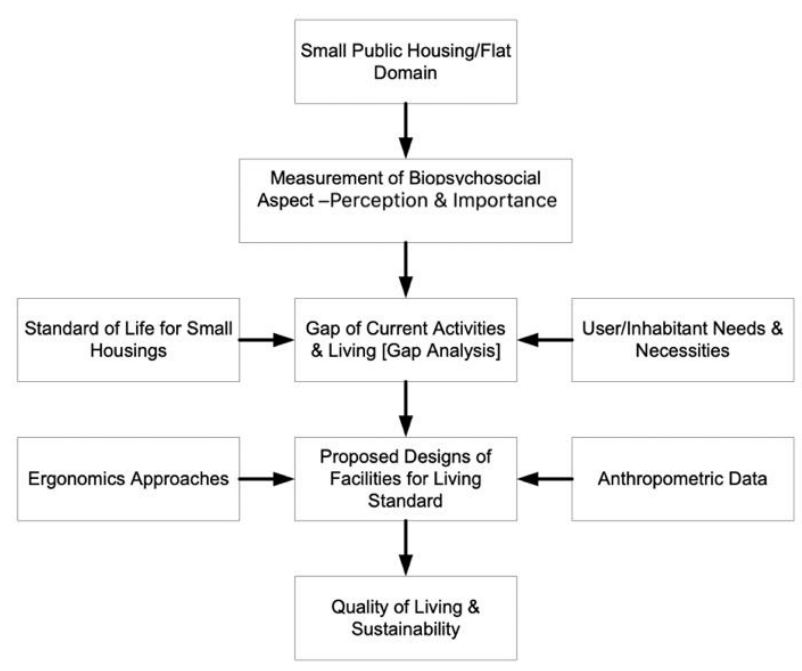

Figure 1. An integrative model of ergo-biopsychosocial approach for QoL in small housing

As it is related to small housing object, the perception of QoL is influenced by ergonomics aspects especially the anthropometry as the representative of physical ergonomics, and environmental ergonomics such as the effects of heat, cold, vibration, noise, and lighting.

The comfort of living in small housing is mainly challenged by physical satisfaction. The physical facilities which correspond to the lowest score of perception of QoL dimension will be prioritized for refinement and redesign. Indonesian anthropometric data will be utilized. The stages of the applicative framework are provided in Figure 1.

Physical facilities are the basic ergonomics for sustainable and comfortable living in a small housing. After the step of mapping of current activities and livings, there would be prioritization of critical ergonomics dimension, which is referred to as physical facilities.

After designing the required physical facilities, the installation and implementation of prioritized physical facilities will be done. The usability testing on the installed physical facilities will be conducted to see its effectiveness and efficiency. A follow-up survey to measure the level of quality of life through WHOQOL-BREF (World Health Organization Quality of Life-BREF) needs to be conducted. It is hoped that a sustainable quality of living will be achieved and improved.

\section{Results and Discussions}

An empirical study on RPS has been conducted. People who were staying in the RPS for at least six months targeted as respondents. This study has been conducted at a range of August 2018 - August 2019. Most of the inhabitants have stayed more than two years at the RPS. 
Table 1. Range of score of quality of work life at the initial stage

\begin{tabular}{llcc}
\hline \multicolumn{1}{c}{ Category } & \multicolumn{1}{c}{ Range of score $(\mathrm{X})$} & Frequency & Percentage (\%) \\
\hline Very high & $\mathrm{X} \geq 109$ & 9 & 10.0 \\
High & $88 \leq \mathrm{X} \leq 108$ & 57 & 63.3 \\
Medium & $68 \leq \mathrm{X} \leq 87$ & 23 & 25.6 \\
Low & $47 \leq \mathrm{X} \leq 67$ & 1 & 1.1 \\
Very low & $\mathrm{X} \leq 46$ & - & - \\
\hline \multicolumn{2}{c}{ Total } & 90 & 100 \\
\hline
\end{tabular}

Table 2. Norms of quality of life at the initial stage

\begin{tabular}{lccc}
\hline \multicolumn{1}{c}{ Aspect } & Mean & Standard Deviation & Category \\
\hline Physical health & 3.70 & 0.46 & High \\
Psychological & 3.77 & 0.45 & High \\
Social Relationship & 3.48 & 0.52 & High \\
Environmental & 3.49 & 0.45 & High \\
\hline
\end{tabular}

First, the initial quality of life (QoL) was measured through WHOQOL-BREF consisting of 4 dimensions (i.e., physical health, social relationship, psychological, and environmental) and 26 items. The perception of current value systems against personal goals has been measured. It was a condition when the inhabitants stayed and performed their daily life at RPS. All variables were deemed reliable and valid.

In gathering more understanding of user needs and problems, in-depth interview (IDI), observation, and focus group discussion (FGD) have been conducted. The findings concluded that more multifunctional furniture, equipment, and public facilities were required. It was due to limited space available in the living room and at the public area. The more interesting finding showed that the low utilization of public facilities due to inconvenient privacy expectation.

The result of QoL distribution is provided (as shown in Table 1). The range of score of QoL was adopted and modified from [12] and [13]. The construct of QoL consists of 26 items with a 5-point Likert scale (ranging from $1=$ strongly disagree to $5=$ strongly agree). The minimum and the maximum possible score is 26 and 130, respectively. The range of score of QoL has 5 categories, i.e., very high $(x>$ mean +1.5 std. dev.), high (mean +0.5 std. dev. $<x<=$ mean +1.5 std. dev.), medium (mean -0.5 std. dev. $<\mathrm{x}<=$ mean +0.5 std. dev.), low (mean -1.5 std. dev. $<x<=$ mean -0.5 std. dev.), and very low ( $x<=$ mean -1.5 std. dev.). The mean score was 94.4 , with a standard deviation of 10.8. It was considered high. Even though the inhabitants felt inconvenient due to very limited space in their living room, they were still quite happy in terms of overall quality of life. It was interesting. So, what made them happy? Only about $27 \%$ of them felt not happy. In other words, less than $50 \%$ perceived low and very low quality of life.

Moreover, the measurement of each dimension of QoL has been done. It shows that the psychological dimension was found to be the most dominant aspect as it had the highest value, i.e., 3.77 out 5 (as shown in Table 2). This psychological dimension deals with emotions, feelings, personal beliefs, self-esteem, and also spirituality. In contrast, the social relationship aspect got the lowest score of 3.48 . It is related to social support and personal relationship. In general, however, all QoL aspects got the category of high. The majority perceived high quality of work-life while they were living in a small housing. It might be understood as Indonesian people mostly have compromised national principles such as working together, caring toward each other, and togetherness. In Javanese, it is called "mangan ora mangan anggere kumpul'. In means that it is not really important to have foods ready on the table, as long as we are always getting together.

Nevertheless, the aspects of social relationship and environmental were very interesting to follow up. Inherently, social and environmental aspects are related to socio-environmental factors. They may be referred to facilities including land, space, physical facilities, utilities, and atmosphere which enhance the quality of social interaction of inhabitants. According to IDI and FGD session with the inhabitants, they insisted that more public facilities for children, parents, and grandparents should have been well provided and maintained. Also, multifunctional furniture to be installed at the unit were expected. Public facilities such as public kitchen, playground, library and reading area, and multipurpose hall were demanded. More specifically, the main concern was on the limited space available. In addition, the limited number of public facilities and movement for inhabitant has been regarded as a significant problem. Inside the inhabitant's room, ironing, washing, and sleeping were deemed a concern as well. As practical implications, some personal and social relationship activities such as social gathering, playing and learning, or even sexual activities will be supported. Based on the result of QoL assessment above especially on the aspect of social and environment and IDI/FGD evaluation on the current physical facilities available in each inhabitant's unit, then the multifunctional facilities and furniture were decided to be a critical need for the inhabitants. Anthropometry and physical ergonomics were applied for the design of multifunctional facilities. According to IDI, FGD, and direct observation, some identified critical facilities and furniture were ironing station, clothesline, bed furniture, public reading room, shoe-rack and bookshelf. Hence, this study addressed these facilities and furniture.

The Indonesian adult anthropometric data have been used. According to the representative user characteristics, a range of stature $150 \mathrm{~cm}$ to $183 \mathrm{~cm}$ was appropriate. It was adopted from 5th to 95th percentile of Indonesian adult stature [8]. 


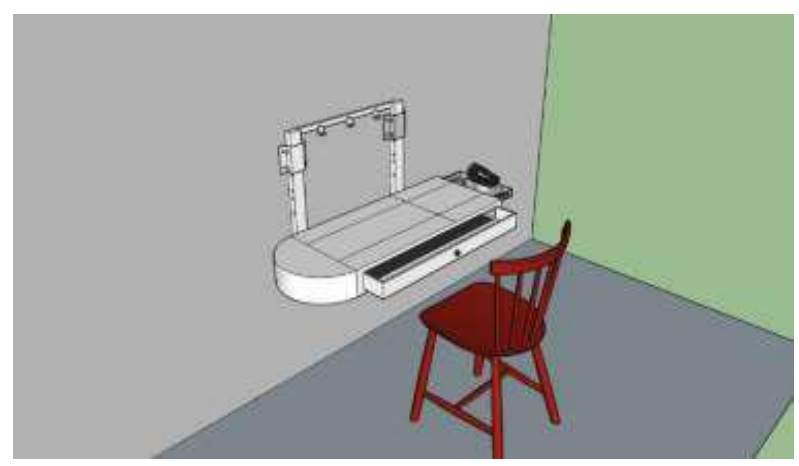

Figure 2. 3D final concept of ironing set

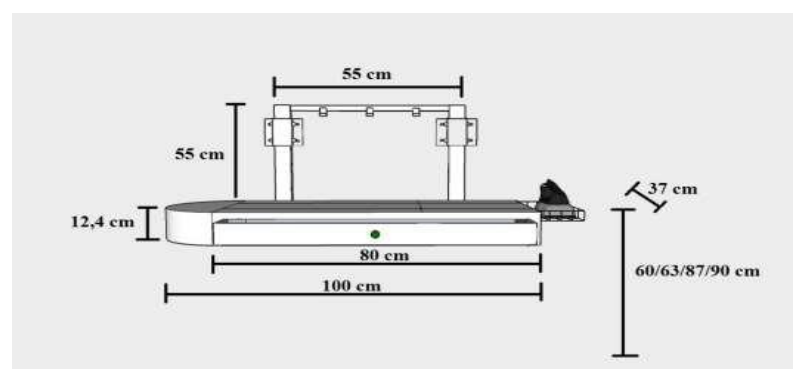

Figure 3. The technical drawings of 3D final concept for ironing set

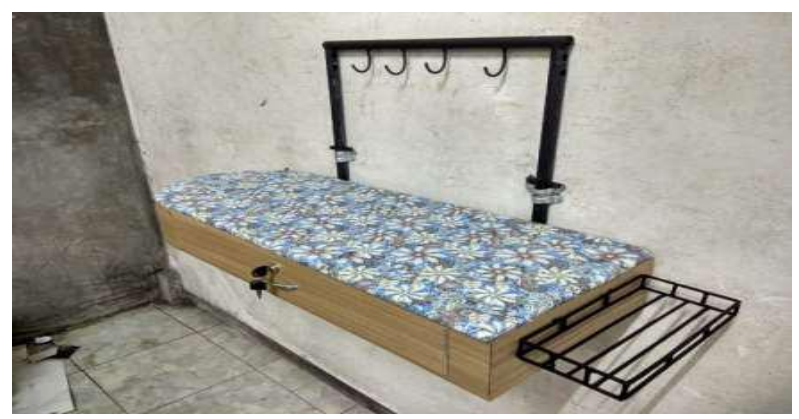

Figure 4. The prototype of the ironing table installed at the unit room

Through the IDI and FGD session, it was found that the inhabitants required multifunctional, lightweight, safe, easy-to-use and -assemble furniture. It seems that they demanded the basic characteristics of the product. With the existing facilities, frequent musculoskeletal disorders (MSD) were found. They includeed waist and back pain, leg cramps, especially for females, did ironing on the floor and low back pain for those putting clothes on the bamboo stick as there was no appropriate and sufficient clothesline.

With regard to inhabitant and user feedbacks for ironing activities, several requirements have been collected, as follow: neat, simple, practical, efficient, strong, cheap, foldable, safe for children, compact, and height adjustable. Through House of Quality (HOQ), all these user requirements (also known as WHAT) were linked to technical requirements or metrics (known as HOW), such as color, dimension, shape, material, height adjustability, and additional functionality. It is to ensure that all user requirements were fully accommodated in the final design. Those series of metrics were then generated to be some possible product concepts. Some alternatives to product concepts were screened and scored, and finally, we had the final concept. The chosen final concept, followed by a prototype, are shown in Figures 2,3 , and 4 . The prototype consists of main components such as multiplex, drawer lock, sponge, fabric, drawer handle, iron pipe, hangers, hook, bolt, pipe clamp, locking rod, and ironing board (as provided in Figure 4).

The prototype has been attached to the RPS complex, at the real one of small housing units. It has been used to see how ironing activities have been done. The users found many benefits of using this ironing station, such as less fatigue on the back, reduce potential musculoskeletal disorders (MSD), and practical use.

Another multifunctional facility was bed furniture. In identifying the user needs, a survey was conducted through IDI. The user requirements were as follow safe, comfortable, interesting, multifunctional, and strong. All these WHAT components were linked to engineering characteristics (HOW) such as size, color, material, mechanism, and model. The more multifunctional and comfortable bed was highly demanded. It was driven by a greater number of family members, given a very standard or even relatively small area for a bedroom. The details of the step-bystep of bed furniture design for a small housing unit were constructed. It was started by the problem identification, concept generation, selection, and testing, and the prototype making, as shown in Figures 5, 6, 7 , and 10 . The prototype consists of four main parts, i.e., bed board, seating board, frame section, and cabinet parts. As a result, the sleeping quality was affected. According to an interview session with the user, she felt relax and more comfortable with the bed furniture. It indicated that the user requirement had been fulfilled.

Another demanded facility was a multifunctional clothesline. Clothesline here is that rods attached between two points used indoors above the level of the ground. It is to facilitate hanging clothes tidier and more practical due to the limited space available. The motivational backgrounds were no proper storage and drying facility in a unit, restriction of using bamboo or similar stick to hang clothes out of the room unit, and limited space available to put and hang clothes. If it was not taken care, the unit room would become more crowded and dirtier. Also, through observation and IDI, some user needs were identified. They included attractive, colorful, neat, spacious, foldable, durable, and easy to use. Similar to the ironing table and bed furniture design, these user 
requirements were linked to engineering characteristics, including material, mechanism, and design. Afterwards, some possible product concepts were generated until the final concept has been chosen.

Through an interview with the user, concept testing has been done as well to see the appropriateness of the proposed design. The user found that the proposed design was practical, easy to use, and attracttive. In general, the prototype consists of one main part, i.e., a clothesline with a capacity of 30 clothes. The chosen final concept and real prototype of the clothesline are provided in Figures 8 and 9.

Afterward, constructive feedbacks from the inhabitants were gathered. The constructive feedbacks were formed in usability testing.

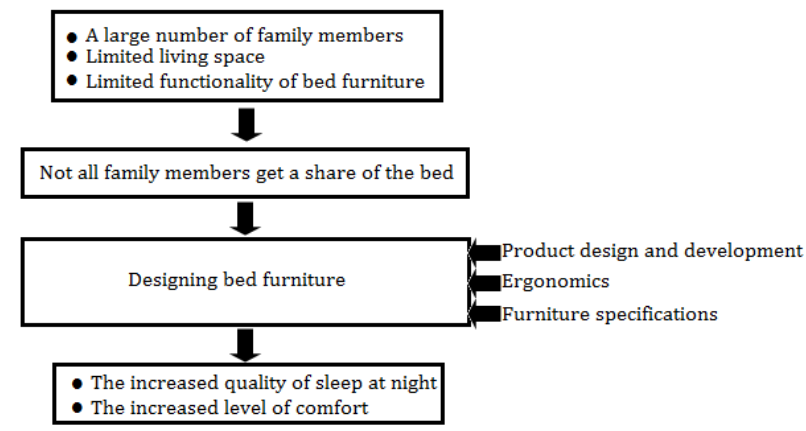

Figure 5. The general design stages for multifunctional bed furniture

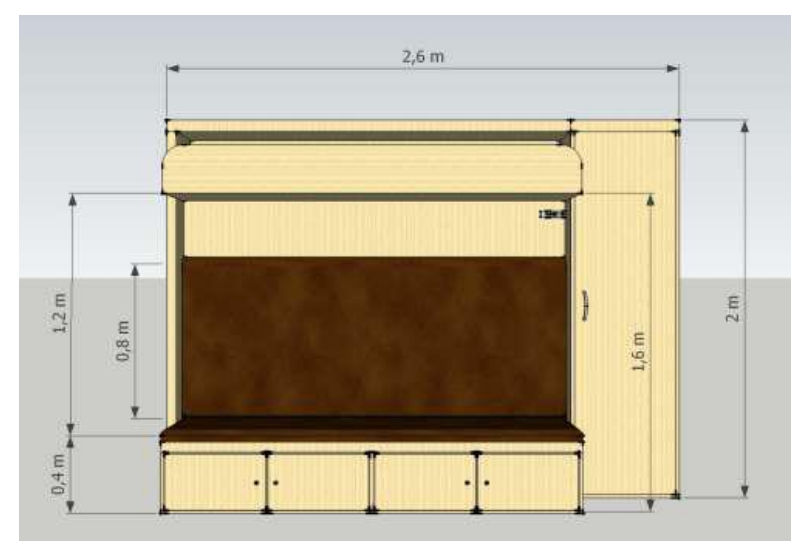

Figure 6. 3D final concept of bed furniture part I

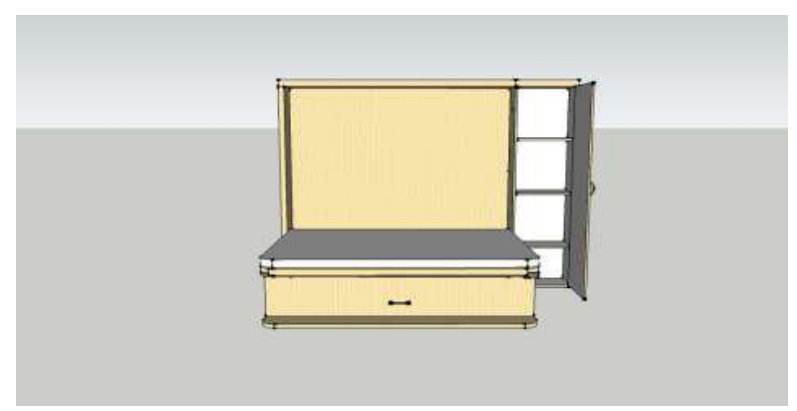

Figure 7. 3D final concept of bed furniture part II

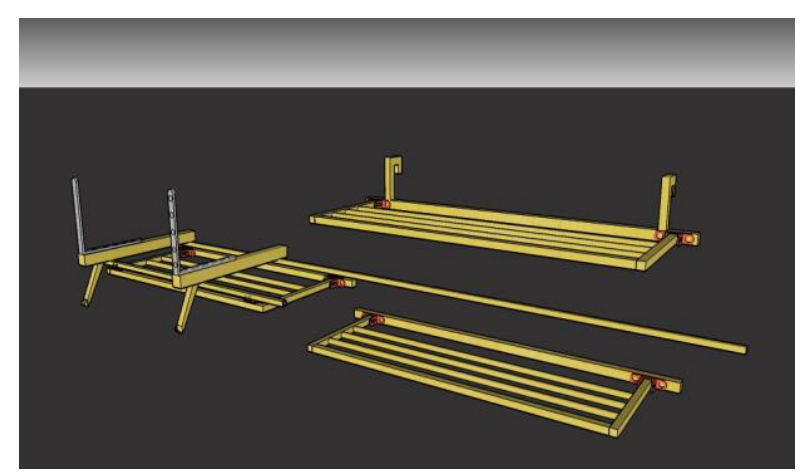

Figure 8. 3D final concept of clothesline part I

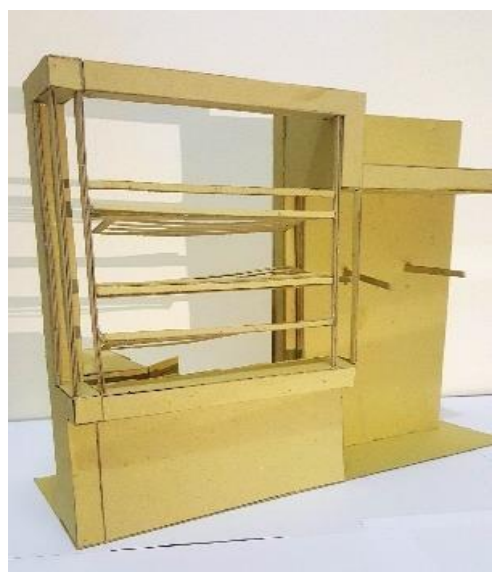

Figure 9. 3D final concept of clothesline part II

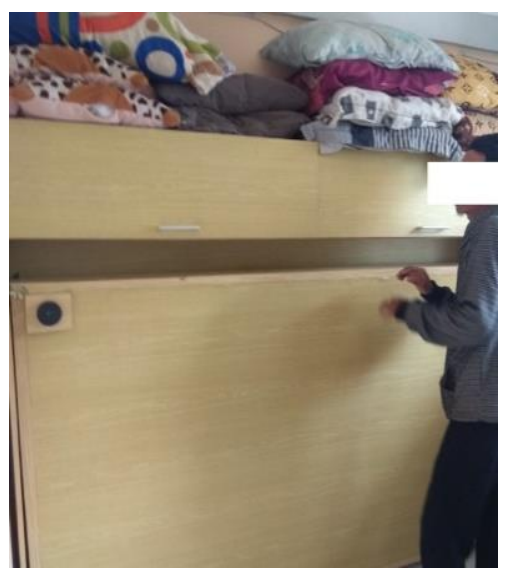

Figure 10. Installation of bed furniture prototype

This study applied purposive sampling. The users were those who have lived in RPS complex for at least two years. Twelve respondents participated in usability testing. They were a subset of ninety samples at the initial study. Usability testing has been adopted from Nielsen Attributes of Usability (NAU) model [14]. The dimensions of usability model consist of efficiency, memorability, learnability, error, and satisfaction. Efficiency is measured by the time to complete a certain task without dismissing the quality. Memorability is assessed by the ease of given tasks to be completed without any given prior instructions. 
Table 3. Usability score for ironing

\begin{tabular}{lcl}
\hline Usability Measure & Average Score (\%*) & Level \\
\hline Memorability & $5.83(83.29 \%)$ & Excellent \\
Errors & $5.71(81.57 \%)$ & Excellent \\
Efficiency & $5.44(77.71 \%)$ & Good \\
Learnability & $6.00(85.71 \%)$ & Excellent \\
Satisfaction & $5.77(82.43 \%)$ & Excellent \\
Grand mean & $\mathbf{5 . 7 7}(\mathbf{8 2 . 4 3 \% )}$ & Excellent \\
\hline
\end{tabular}

*Level \&\% are defined by the average score against the total score of 7

Table 4. Expected time for ironing

\begin{tabular}{lc}
\hline \multicolumn{1}{c}{ Task } & Completion Time (seconds) \\
\hline Open the table and place the iron & 7.25 \\
Table settings for standing iron & 12.78 \\
Table settings for sitting iron & 12.26 \\
Close the table and return the table & 13.58 \\
to its initial position & \\
\hline
\end{tabular}

Learnability is discussed through a condition whether it is easy or not to learn a new proposed product. Error is measured by the number of discrepancies between what has been instructed and what has been accomplished. Satisfaction is approached by the overall impression when a user has already tested the product.

The result of usability testing is provided in Tables 3 and 4. It was applied to the ironing activities. The range of measurement scale is between 1 (the lowest) and 7 (the highest).

Concerning the result of usability test (see Tables 3 and 4), it seemed that efficiency was found to be a concern for the majority. It might be due to some adjustments such as a relative heavy table, adjustability of table height, difficulty to decouple table from the locking mechanism, and unstable structure of the locking mechanism. These findings were useful to be inputs for the prototype refinement.

Apart from ironing activities, the bed furniture usability test provided very good results on five aspects of Nielsen Attributes Usability (NAU), as explained as follows. At the "memorability" criterion, there was no problem with the memorability aspect of using this bed. Respondents understood and memorized well the setting and installation path from the chair to the bed and vice versa. Because it was easy to remember, respondents were also sure that they would be able to do the installation again after one month. Related to the "error" aspect, respondents did not make any mistakes when setting up this product. Bed boards were also not easy to fall when installing into a bed or chair. In addition, cabinets and drawers also did not open easily on their own. "Efficiency" aspect has been proven by the completion time needed for setting up the bed. It only took 19 seconds to set the bed and 16 seconds to reverse it as before. Respondents felt that in setting this bed did not require a long time. In addition, with this product, the laying of clothes and goods become neater, and respondents could make the most of the room. In terms of "learnability", respondents did not find it difficult to learn in using this product. Respondents felt they can learn quickly and easily do the installlation and can learn without written instructtions. Finally, at the "satisfaction" criterion, respondents were satisfied with this product and surely hoping to have this product in their room. Respondents felt comfortable and enjoyed the additional functions of this product.

Moreover, respondents would like to recommend this furniture product to others. Additionally, according to respondents' feedback and evaluation, this product can also be used to store pillows, bolsters, and blankets. The product's dimension was considered quite wide with a very strong hook. Although it's considered good, respondents gave some insightful recommendation such as, (i) the back that attaches to the wall should be coated with plastic because the wall is damp, (ii) the lock when folding the mattress should be longer for safety, (iii) the mechanism of lowering the bed should be further developed so that it can be easily done by women or children, and (iv) the development of bunk beds in the future is prospective.

Two similar product types, i.e., shoe-rack and bookshelf, have been gone through usability tests as well. The result of qualitative usability test for shoerack and bookshelf is shown in Table 5. This condition made the children reading room tidier and cleaner, as shown in Figure 11.

After the serial implementation of ergonomic-based designed facilities, a subsequent survey involving 82 respondents (40 females [49\%] and 42 males [51\%]) has been conducted to measure the perception of the quality of life through WHOQOL-BREF. They were a subset of the 90 samples of the initial study. The distribution of quality of life (QoL) scores for RPS inhabitants after the implementation of ergonomicsbased physical facilities is summarized and provided in Table 6. The mean and standard deviation of QoL score was 95.2 and 10.3, respectively. The majority perceived that the respondents had a relatively high quality of life (54 out of 82 respondents [54\%]). The quality of life norms also shows that all aspects of quality of life have high value, as shown in Table 7. The implementation score is then compared with the initial score, as shown in Table 8.

The results, as provided in Tables $1,2,6,7$, and 8 show that there is a tendency to improve the quality of life due to the implementation of ergonomics-based physical facilities. The aspect of social relationship 
Table 5. Result of qualitative usability test for shoe-rack and bookshelf

\begin{tabular}{|c|c|c|}
\hline Usability Measure & \begin{tabular}{|l} 
Shoe-rack \\
\end{tabular} & $\begin{array}{c}\text { Bookshelf } \\
\end{array}$ \\
\hline Memorability & $\begin{array}{l}\text { It was considered very well. Respondents easily } \\
\text { remembered where to place their shoes. In addition, } \\
\text { respondents would not forget where to place shoes even } \\
\text { after one month. }\end{array}$ & $\begin{array}{l}\text { Respondents had no problem remembering the } \\
\text { placement of books and toys on the shelf. In addition, } \\
\text { respondents would not forget where they were } \\
\text { located, even after one month. }\end{array}$ \\
\hline Errors & $\begin{array}{l}\text { Errors in product use were not felt by respondents, } \\
\text { evidenced by respondents not making any mistakes in } \\
\text { putting shoes. In addition, the shoe drawers did not easily } \\
\text { open. }\end{array}$ & $\begin{array}{l}\text { Similar to what was found in shoe-rack, respondents } \\
\text { also did not make mistakes in placing books and } \\
\text { toys. The bookcase and toy drawer were also } \\
\text { ergonomically designed. }\end{array}$ \\
\hline Efficiency & $\begin{array}{l}\text { This shoe rack helped respondents not to be confused } \\
\text { about finding a place to put their shoes. In addition, } \\
\text { respondents felt that by using this product the laying of } \\
\text { shoes became tidier, quicker, and easier. }\end{array}$ & $\begin{array}{l}\text { Respondents found it very fast and easy to put down } \\
\text { and pick-up books and toys. The books and toys were } \\
\text { put neatly. }\end{array}$ \\
\hline Learnability & $\begin{array}{l}\text { Respondents learned to use this shoe rack quickly and } \\
\text { easily even without written instructions. }\end{array}$ & $\begin{array}{l}\text { Respondents learned to use this bookshelf quickly } \\
\text { and easily even without written instructions. }\end{array}$ \\
\hline Satisfaction & Respondents were satisfied with using this product. & $\begin{array}{l}\text { Respondents felt comfortable and enjoyed the } \\
\text { functions of this product. }\end{array}$ \\
\hline $\begin{array}{l}\text { Additional } \\
\text { feedback/recommendation }\end{array}$ & $\begin{array}{l}\text { The edges of the chair should be made blunt so as not to } \\
\text { scratch the legs. We recommend adding a lock to the shelf } \\
\text { to maintain shoe safety. }\end{array}$ & $\begin{array}{l}\text { The bookshelves should be adjusted to the condition } \\
\text { of the humid flat wall and/or we can add plastic to } \\
\text { the back of the bookshelf so that it is not porous. } \\
\text { f Also, we need to pay more attention to the strength } \\
\text { and durability of the material whether it is able to } \\
\text { accommodate and withstand the heavy loads (e.g., } \\
\text { thick archived documents) }\end{array}$ \\
\hline
\end{tabular}
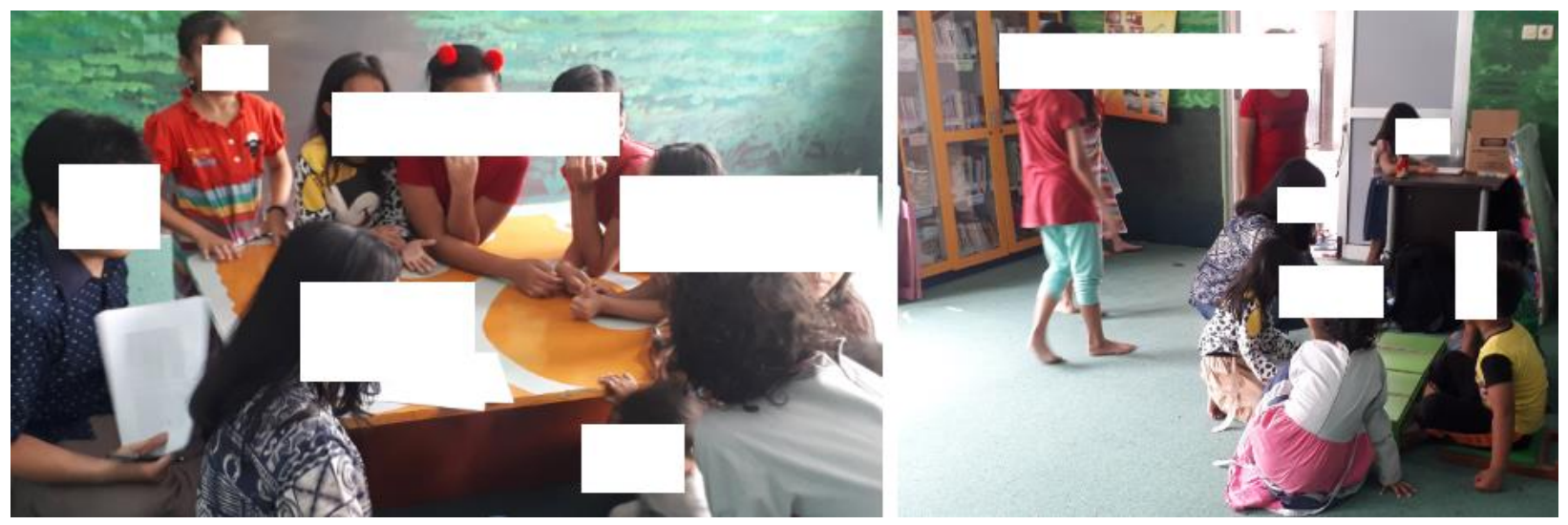

Figure 11. Implementation of children's reading room

tended to be a dominant change. However, since the duration of implementation was about six months, it is too early to conclude that the improvement of quality of life scores was only due to the installed ergonomics-based facilities.

According to the positive $\Delta$ values shown in Table 8 , in general, it seemed that ergonomics intervention and modification supported the quality of life for all aspects (i.e., physical, psychological, social relationship, and environmental). More specifically, referring to the social relationship and environmental aspects at the initial stage as the primary concern, this study has shown that the proposed redesigned facilities and furniture brought a positive impact on the QoL of inhabitants. Although these positive $\Delta$ values were relatively low, there was a tendency that these values will increase in the future. It was likely due to the relatively short trial period of the proposed facilities. The inhabitant as a user was still at the stage of habituation. It may follow the learning curve, which is an increase in learning comes from more and greater experience. Learning curves are deemed effecttive for monitoring the performance of people exposed to a new task and environment [15]. In other words, the more someone does and performs a specific and the same task, the better they get at it. Learning curves have been initially empirically proven in the study of aircraft assembly. The cost of aircraft assembly has been reduced at a constant rate as the number of assembled aircraft doubled. It shows that people are well trained and improved once they do the same things frequently given a standard procedure.

\section{Conclusion}

This study tried to address the formulation of an integrative model of ergo-biopsychosocial related to QoL of inhabitants in a small housing complex (known as flat). Besides, a case study on a small housing complex has been conducted to validate the applicability of the proposed model. 
Table 6. Distribution of quality of life for RPS inhabitants after the implementation stage

\begin{tabular}{lccc}
\hline \multicolumn{1}{c}{ Category } & Range of score $(\mathrm{X})$ & Frequency & Percentage (\%) \\
\hline Very high & $\mathrm{X} \geq 109$ & 14 & 17.1 \\
High & $88 \leq \mathrm{X} \leq 108$ & 54 & 65.9 \\
Medium & $68 \leq \mathrm{X} \leq 87$ & 14 & 17.1 \\
Low & $47 \leq \mathrm{X} \leq 67$ & - & - \\
Very low & $\mathrm{X} \leq 46$ & - & - \\
\hline \multicolumn{2}{c}{ Total } & 82 & 100 \\
\hline
\end{tabular}

Table 7. Norms of quality of life after the implementation stage

\begin{tabular}{lccc}
\hline Aspect & Mean & $\begin{array}{c}\text { Standard } \\
\text { Deviation }\end{array}$ & Category \\
\hline Physical Health & 3.82 & 0.41 & High \\
Psychological & 3.89 & 0.48 & High \\
Social Relationship & 3.78 & 0.53 & High \\
Environmental & $3.74^{*}$ & 0.64 & High \\
\hline *note: some efforts need to be done for the aspect & \\
"environmental aspect" & &
\end{tabular}

Table 8. Comparison of quality of life scores between before and after the implementation of ergonomics-based facilities

\begin{tabular}{lccc}
\hline Aspect & Before & After & $\Delta^{*}$ \\
\hline Physical Health & 3.70 & 3.82 & 0.12 \\
Psychological & 3.77 & 3.89 & 0.12 \\
Social Relationship & 3.48 & 3.78 & 0.30 \\
Environmental & 3.49 & 3.74 & 0.25 \\
\hline *note: $\Delta=$ after - before & & &
\end{tabular}

The findings showed that there was a closed relationship between the comfort of the physical environment and the satisfaction of biopsychosocial aspects of inhabitants. It covers the quality of human life and social interaction among inhabitants. More specifically and significantly, this study showed that the quality of housing was associated with quality of life. The crowd accompanied by a limited number and space of multifunctional facilities and furniture brought significant impact on individual stress. This study was in line with the previous research, proofing that both physical and mental health was influenced by the condition of a home.

Nevertheless, this study has limitations. This study still focused on qualitative research methodology. By looking at the dynamics of inhabitants needs and lifestyles and growth of population, given limited space for housing complex, an engineering-based simulation system for physical facilities and inhabitant activities are required. They might include a parking lot, in-house gardening, public library and kitchen scheduling, and fire drilling. After testing the final prototypes, it seemed that there was an increase in quality of life for inhabitants. However, it might be pseudo conditions due to a limited number of respondents involved and also the short duration of implementation. In addition, a periodic observation and measurement of QoL for inhabitants should be conducted, for instance, a semi-annual QoL assessment.

\section{Acknowledgment}

Authors would like to thank the anonymous reviewers, and Ministry of Research, Technology, and Higher Education Republic of Indonesia for the competitive grant scheme PTUPT 2018 - 2019.

\section{References}

1. World Health Organization, WHOQOL-BREF: Introduction, Administration, Scoring, and Generic Version of the Assessment, Geneva: WHO, 2004.

2. Diener, E., Diener, M., and Diener, C., Factors predicting the subjective well-being of nations. In: Diener, E. Culture and Well-Being: The Collected Works of Ed Diener, Social Indicators Research Series, London: Springer, 38, 2009, pp. 43-70.

3. Oliveira, R. C., and Elali, G. A., Minimum Housing Spaces, Flexibility, and Sustainability: A Reflection on the Basis of Ergonomics Intervention, Work, 41, 2012, pp. 1409-1416.

4. IEA, International Ergonomics Association, retrieved from https://www.iea.cc/ on 10 January 2020.

5. Engel, G. L., The Need for a New Medical Model: A Challenge for Biomedicine, Holistic Medicine, 4(1), 2009, pp. $37-53$.

6. Barcaccia, B., Quality of Life: Everyone Wants It, But What is It? Forbes/Education, 2013.

7. Frankenhaeuser, M., A Biopsychosocial Approach to Work Life Issues, International Journal of Health Services, 19(4), 1989, pp. 747 758.

8. Tan, K. C., Hartono, M., and Kumar, N., Anthropometry of the Singaporean and Indonesian Populations, International Journal of Industrial Ergonomics, 40(6), 2010, pp. 757 - 766 .

9. Hartono, M., Indonesian Anthropometry Update for Special Populations Incorporating Drillis and Contini Revisited, International Journal of Industrial Ergonomics, 64, 2018, pp. 89 - 101.

10. Guimaraes, B. M., Ergonomics and workplace adaptation to people with disabilities, Work, 50, 2015, pp. $607-609$.

11. Millera, L., Dorseyb, J., and Jacobs, K., The Importance of Ergonomics to Sustainability throughout a Building's Life Cycle, Work, 41, 2012, pp. 2129-2132.

12. Kelbiso, L., Belay, A., and Woldie, M., Determinants of Quality of Work Life among Nurses Working in Hawassa Town Public Health Facilities, South Ethiopia: A Cross-Sectional Study, Nursing Research and Practice, 2017.

13. Azwar, S., Penyusunan Skala Psikologi, Edisi 2, Yogyakarta: Pustaka Pelajar, 2012. 
14. Nielsen, J. Usability Engineering, Mountainview, California: SunSoft, 1993.

15. Anzanello, M. J., and Fogliatto, F. S., Learning
Curve Models and Applications: Literature Review and Research Directions, International Journal of Industrial Ergonomics, 41, 2011, pp. $573-583$. 